
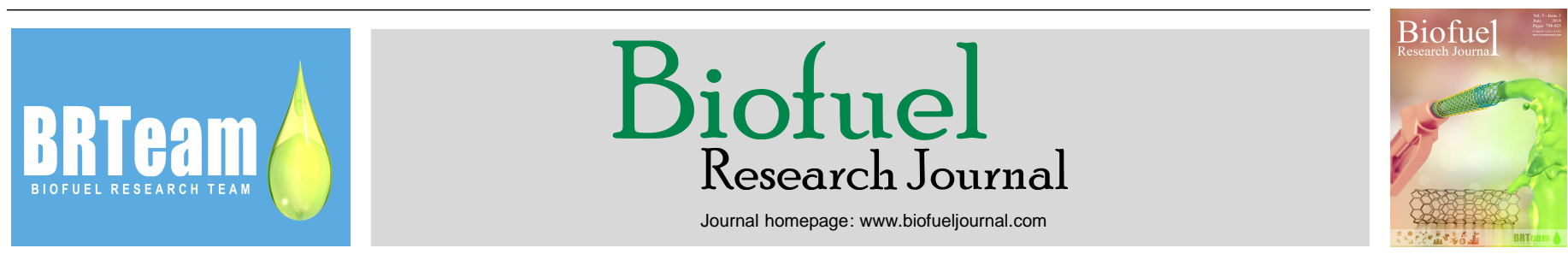

Original Research Paper

\title{
Magnetically recyclable nanocatalysts based on magnetite: an environmentally friendly and recyclable catalyst for esterification reactions
}

Vannia Cristina dos Santos-Durndell, Tailor Machado Peruzzolo, Geani Maria Ucoski, Luiz Pereira Ramos, Shirley Nakagaki*

Laboratório de Química Bioinorgânica e Catálise, Universidade Federal do Paraná(UFPR), Departamento de Química, Centro Politécnico, CP 19072, CEP

81531-980, Curitiba, Paraná, Brazil.

\section{HIGHLIGHTS}

$>\mathrm{Fe}_{3} \mathrm{O}_{4} / \mathrm{SiO}_{2}$ as an efficient and inexpensive catalyst for esterification reaction.

$>$ The structure of the catalytic species $\mathrm{Fe}_{3} \mathrm{O}_{4}$ was maintained for four catalytic cycles.

$>$ Coating magnetic particles with silica prevented crystal aggregation.

$>$ The advantage of coating the magnetic nanoparticles with silica was experimentally demonstrated.

\section{GRAPHICAL ABSTRACT}
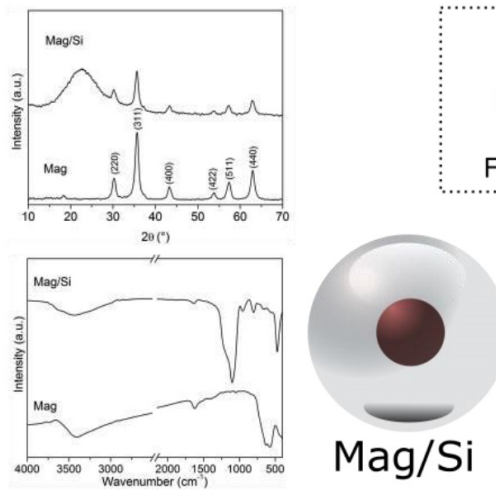<smiles>[R]C(=O)O[13CH2]O[13CH3]</smiles>

Alkyl ester

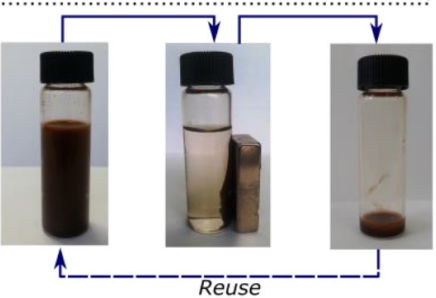

\section{ARTICLE INFO}

\section{Article history:}

Received 16 December 2017

Received in revised form 22 March 2018

Accepted 7 April 2018

Available online 1 June 2018

\section{Keywords:}

Magnetite

Silica

Esterification

Fatty acid methyl esters

Biodiesel

\begin{abstract}
Solid magnetic nanoparticles (magnetite $=$ Mag) composed of $\mathrm{Fe}_{3} \mathrm{O}_{4}$ and magnetite coated with silica $\left(\mathrm{Fe}_{3} \mathrm{O}_{4} / \mathrm{SiO}_{2}=\mathrm{Mag} / \mathrm{Si}\right.$ ) were prepared from inexpensive starting materials. The catalytic activity of the solids was investigated for palmitic acid esterification with methanol under solvothermal conditions. Both pure $\mathrm{Fe}_{3} \mathrm{O}_{4}$ (Mag) and silica-coated (Mag/Si) nanoparticles exhibited high catalytic activities and were easy to recover from the reaction environment using an external magnet. Furthermore, the magnetic nanoparticle catalysts were reused without significant loss of catalytic activity and showed high durability in typical acid-catalyzed reactions. XRD and SEM analyses were conducted before and after esterification, showing almost identical particle distribution in both fresh and reused catalysts.
\end{abstract}

* Corresponding author at: Tel.: +55 41333613180

E-mail address: shirleyn@ufpr.b

Please cite this article as: dos Santos-Durndell V.C., Peruzzolo T.M., Ucoski G.M., Ramos L.P., Nakagaki S. Magnetically recyclable nanocatalysts based on magnetite: an environmentally friendly and recyclable catalyst for esterification reactions. Biofuel Research Journal 18 (2018) 806-812. DOI: 10.18331/BRJ2018.5.2.4 


\section{Introduction}

The class of organic ester compounds has become increasingly important in recent decades due to the range of industrial applications for production of beverages, foods, pharmaceuticals, perfumes, flavorings, plasticizers, solvents, chemical intermediates, and many other products (Ansari et al., 1974; Nishikubo et al., 1996; Chapuis et al., 2001; Monteiro et al., 2004; Yadav et al., 2004; Mansoori et al., 2005; Gallezot, 2007; Lenardão et al., 2007; Serri et al., 2010; Schwab et al., 2013; Paiva et al., 2015). In addition to that, this class of compounds has attracted particular attention because of its relevance as a viable alternative for partial or full replacement of petroleum diesel, without the need for significant changes in diesel engines (Carmo et al., 2009; Demirbas, 2009; Avhad et al., 2016).

Biodiesel is a mixture of alkyl esters that can be obtained by esterification of free fatty acids or by transesterification of vegetable or animal oils and fats with short-chain alcohols, catalyzed by homogeneous or heterogeneous, enzymes, or hybrid phase catalysts (Zhang et al., 2003; Lois et al., 2007; dos Santos et al., 2011; Lee et al., 2014; Santos et al., 2014).

In comparison with its fossil fuel analog, biodiesel is characterized as renewable, non-toxic, easy to store, and more biodegradable, but it is more expensive due to its high production cost since the current processes require high power and materials consumption (Zhang, 2012). In light of that, there has been a strong research activity aimed at finding more efficient alkyl ester production processes, thus increasing the competitiveness of biodiesel against petroleum diesel (Demirbas, 2009; Tabatabaei et al., 2015; Gumba et al., 2016; Knothe, 2017). Much of this research focuses on the development of new catalysts for heterogeneous catalytic processes, which can become a viable alternative to the current production processes using homogeneous catalysts. Although homogeneous processes have high conversion values with the use of soluble catalysts that present high catalytic activity and ease of operation, these processes can present significant drawbacks such as high corrosion of equipment, need for numerous separation and purification processes, and inability to recover the catalyst at the end of the process, collectively increasing the overall process cost while also making the process environmentally unsustainable (Ma et al., 1999; Frondel et al., 2007; Demirbas, 2009; Semwal et al., 2011; Chuah et al., 2017).

Besides the possibility of obtaining products with higher purities in fewer steps than in homogeneous processes and the advantage of performing the recycling and reuse of catalysts, heterogeneous catalytic processes also offer, at least in theory, a greater versatility for adaptation to different process conditions and reactive systems. This translates into the development of leaner processes in which separation steps such as filtration and centrifugation are avoided, making the process more efficient (Ma et al., 1999; Cantrell et al., 2005; Lois, 2007; Carmo et al., 2009; Yan et al., 2009; dos Santos et al., 2011; Gumba et al., 2016; Silva et al., 2017).

One of the major challenges in the catalysis arena is the development of new solids for heterogeneous catalytic processes that meet both efficiency and selectivity criteria while allowing recovery, reactivation, and reuse during numerous cycles, without mass losses. In this sense, magnetic particles are potential solids for catalytic research since their recovery and reuse can be easily achieved by the use of magnets as opposed to conventional separation methods (Polshettiwar et al., 2011; Lopez et al., 2014). In fact, magnetic nanoparticles have been mainly investigated as an easy way to recover/remove the solid catalyst from the catalytic reaction. There are many examples of the use of magnetite $\left(\mathrm{Fe}_{3} \mathrm{O}_{4}\right)$ as a platform for catalytic species (Polshettiwar et al., 2011; Rossi et al., 2012; Ucoski et al., 2013). Magnetite was also used as adsorbent solid for the removal of fatty acids from organic solutions and vegetable oils (Cano et al., 2012). At room temperature, the adsorption of oleic acid from ethanol-hexane solutions was investigated using equilibrium batch experiments. The results showed that the adsorption was rapid $(<2 \mathrm{~h})$ and followed a pseudo-second-order model. The magnetic properties of the solid were also explored in a recycling adsorption experiment (Cano et al., 2012).

The magnetic properties of solid magnetite $\left(\mathrm{Fe}_{3} \mathrm{O}_{4}\right)$ are related to its chemical and morphological characteristics as well the particle size. It presents a cubic crystal system with inverted spinel structure, where the unit cell comprises $\mathrm{O}^{2-}$ ions coordinated with $\mathrm{Fe}$ (II) and $\mathrm{Fe}$ (III) ions. The $\mathrm{Fe}(\mathrm{II})$ ions are coordinated in an octahedral structure while $\mathrm{Fe}(\mathrm{III})$ ions are coordinated in both octahedral and tetrahedral structures. Since the $\mathrm{Fe}(\mathrm{III})$ ions are equally coordinated in tetrahedral and octahedral frameworks, there is no magnetic moment resulting from the presence of these ions. However, all $\mathrm{Fe}(\mathrm{II})$ ions are only in octahedral structures, being responsible for saturation magnetization, that is, the magnetic behavior of the material, causing it to be superparamagnetic (Cornell et al., 2003; Friak et al., 2007; Yang et al., 2011).

Unlike the many studies that have used magnetic particles as part of catalytic solids in heterogeneous process, there are few reports on the catalytic aspects of this family of solids for catalytic processes related to biofuel. Regarding magnetic particles only, there are some recent reports discussing their application, mainly examining $\mathrm{Fe}_{3} \mathrm{O}_{4}$ magnetite as a solid platform for the preparation of magnetic solids for use in catalysis processes (Guo et al., 2012; Tang et al., 2012; Lopez et al., 2014). The association of an enzyme with magnetite has also been reported for catalytic purposes (Xu et al., 2004; Lee et al., 2007; Ren et al., 2011; Black et al., 2013; Lopez et al., 2014) including lipase and magnetite associations to produce fatty acid alkyl esters (Lopez et al., 2014; Andrade et al., 2016).

In the present work, the use of magnetic particles based on pure magnetic iron oxide $\left(\mathrm{Fe}_{3} \mathrm{O}_{4}=\mathrm{Mag}\right)$ and magnetic particles coated with silica $\left(\mathrm{Fe}_{3} \mathrm{O}_{4} / \mathrm{SiO}_{2}=\mathrm{Mag} / \mathrm{Si}\right)$ were investigated as catalysts for heterogeneous esterification of palmitic acid by methanol in a solvothermal system at 120 ${ }^{\circ} \mathrm{C}$ and not as support for any other catalytic species.

\section{Materials and Methods}

\subsection{Catalyst preparation (Mag and Mag/Si)}

Solid $\mathrm{Fe}_{3} \mathrm{O}_{4}$ nanoparticles (Mag) was prepared by a simple coprecipitation method using $\mathrm{FeCl}_{2}$ and $\mathrm{FeCl}_{3}$ in alkaline conditions (Philipse et al., 1994). The solid magnetite coated with silica was obtained using the hydrolytic sol-gel process $\left(\mathrm{Fe}_{3} \mathrm{O}_{4} / \mathrm{SiO}_{2}=\mathrm{Mag} / \mathrm{Si}\right)$ (Stöber et al., 1968), as reported previously by Ucoski et al. (2013), following the modifications described by Yi et al. (2006) and Wang et al. (2008). Briefly, the synthesis was carried out in five steps. In the first step, mild sonication was used to dissolve $11.2 \mathrm{~mL}$ of Igepal CO-520 in $20 \mathrm{~mL}$ of cyclohexane. The ethanol suspension $(2 \mathrm{~mL})$ of the previously prepared Mag was added, and the mixture was sonicated for $1 \mathrm{~h}$. Then, $28 \%$ aqueous ammonia $\left(1.9 \times 10^{-1} \mathrm{~mol}\right)$ and a volume of tetraethyl orthosilicate (TEOS; $2.9 \times 10^{-2} \mathrm{~mol}$ ) were added dropwise, and the suspension was left undisturbed for $48 \mathrm{~h}$. In the second step, the obtained suspension was washed with ethanol $(5 \times 52 \mathrm{~mL})$, and Mag coated with silica (Mag/Si) was separated from the solution using a magnet. In the third step, Mag/Si was treated with $52 \mathrm{~mL}$ of ethanol, and the suspension was sonicated for several minutes, until all the solid was dispersed in the solvent. More ethanol $(112 \mathrm{~mL})$ and deionized water $(74$ $\mathrm{mL}$ ) were added, and sonication was continued for $1 \mathrm{~h}$. Subsequently, $28 \%$ aqueous ammonia $\left(1.7 \times 10^{-1} \mathrm{~mol}\right)$ was added under vigorous stirring. Finally, TEOS $\left(9.6 \times 10^{-2} \mathrm{~mol}\right)$ was introduced four times at $12 \mathrm{~h}$ intervals. In the fourth step, $\mathrm{Mag} / \mathrm{Si}$ was separated from the suspension using a magnet and added to a mixture of $28 \%$ aqueous ammonia $\left(6.3 \times 10^{-2} \mathrm{~mol}\right)$ and deionized water $(20 \mathrm{~mL})$. The suspension was left undisturbed for 12 $\mathrm{h}$. In the fifth and last step, the isolated Mag/Si was mixed with $3 \%$ aqueous ammonia $(4 \mathrm{~mL})$ and deionized water $(6 \mathrm{~mL})$. The suspension was left at rest for $24 \mathrm{~h}$, after which the supernatant was removed and the solid was dried at $80{ }^{\circ} \mathrm{C}$ in an oven.

\subsection{Catalyst characterization}

Power X-ray diffraction patterns (XRD) were collected with a Shimadzu XRD-6000 diffractometer (Cu K $\mathrm{K}_{\alpha} 1.54 \AA, 40 \mathrm{kV}$ and $\left.20 \mathrm{~mA}\right)$. Scanning electron microscopy and energy dispersive X-ray elemental analysis (SEM/EDX) was performed with a JEOL/JSM-6360LV microscope operating at $110 \mathrm{kV}$. Transmission electron microscopy (TEM) was carried out with a JEOL-JEM 1200 EWII microscope operating at $120 \mathrm{kV}$ and the infrared vibrational spectra were collected with a BIO-RAD $3500 \mathrm{GX}$ spectrometer, scanning from 400 to $4000 \mathrm{~cm}^{-1}$ using a KBr pellet with $4 \mathrm{~cm}^{-}$ ${ }^{1}$ resolution and accumulation of 32 scans.

\subsection{Catalytic activity}

Palmitic acid esterification reaction using the solids Mag and Mag/Si was performed under solvothermal conditions inside an oven using a $15 \mathrm{~mL}$ closed Teflon cup fitted into a closed stainless steel reactor vessel (Santos 
et al., 2015). Reactions were conducted using a $n_{\mathrm{MeOH}} / n_{\text {acid }}$ molar ratio of 12 and $10 \mathrm{wt} . \%$ of catalyst in relation to the acid weight, with the thermal bath set to $120^{\circ} \mathrm{C}$. After cooling to room temperature, the catalyst was separated from the reaction mixture (using a simple magnet) and recovered for reuse (Santos et al., 2015). To this end, the catalysts were washed with methanol and ethanol (10 $\mathrm{mL}$ ) (Ma et al., 1999), dried at $120{ }^{\circ} \mathrm{C}$, and their recycling capacity was evaluated in sequential reactions using the same experimental conditions. The excess alcohol was removed by evaporation under low pressure, and the conversion of the fatty acid to alkyl esters was performed by titration of the remaining acid using a $0.01 \mathrm{~mol} \mathrm{~L}^{-1} \mathrm{NaOH}$ standard solution, while methyl palmitate was the only produced alkyl ester expected in this reaction.

\section{Results and Discussion}

\subsection{Catalyst characterization}

A schematic illustration of the synthetic pathway for obtaining $\mathrm{Fe}_{3} \mathrm{O}_{4} / \mathrm{SiO}_{2}$ (Mag/Si) is shown in Figure 1. The $\mathrm{Fe}_{3} \mathrm{O}_{4}$ magnetic nanoparticles (Mag) were synthesized using a simple co-precipitation method from $\mathrm{FeCl}_{3}$ and $\mathrm{FeCl}_{2}$ under alkaline conditions (Philipse et al., 1994). To coat the $\mathrm{Fe}_{3} \mathrm{O}_{4}$ with silica, a reverse microemulsion method using Igepal in cyclohexane was used (Fig. 1). The resulting reverse micelles stabilized the $\mathrm{Fe}_{3} \mathrm{O}_{4}$ particles, avoiding particles agglomeration and also acted as microreactors in the confined sol-gel method, where the spherical material was formed by the hydrolysis of TEOS as silica source. Coating $\mathrm{Fe}_{3} \mathrm{O}_{4}$ with silica particles could improve the stabilization under reaction conditions while at the same time maintaining the magnetic properties.

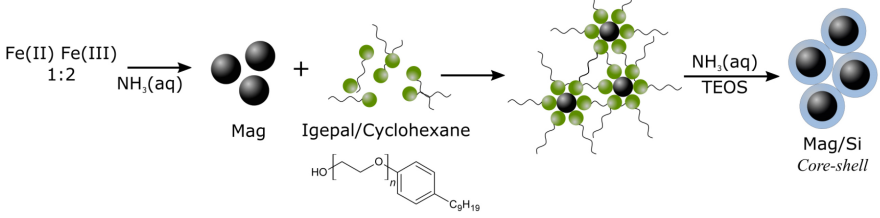

Fig.1. Schematic illustration of the synthesis of the magnetic solid $\mathrm{Mag} / \mathrm{Si}\left(\mathrm{Fe}_{3} \mathrm{O}_{4} / \mathrm{SiO}_{2}=\mathrm{Mag} / \mathrm{Si}\right)$.

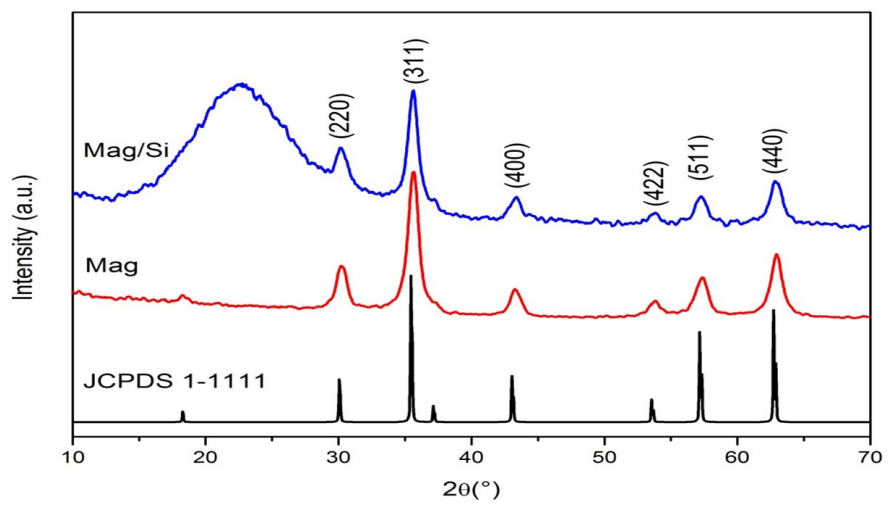

Fig.2. Powder X-ray diffraction patterns of $\mathrm{Mag}$ solid $\left(\mathrm{Fe}_{3} \mathrm{O}_{4}\right)$ before and after coating with $\mathrm{SiO}_{2}$ $\left(\mathrm{Fe}_{3} \mathrm{O}_{4} / \mathrm{SiO}_{2}=\mathrm{Mag} / \mathrm{Si}\right)$. Spinel structure of pure magnetite $\left(\mathrm{Fe}_{3} \mathrm{O}_{4}\right)$ is given by JCPDS card 1 1111.

Figure 2 shows the XRD patterns of the Mag nanoparticles. Mag solid exhibited characteristic reflections of spinel structure according to the reflections by their indices ((220), (311), (400), (422), (511), and (440)) (JCPDS card 1-1111). After coating with silica, the same patterns were observed as well as a broad peak around $20-30^{\circ}\left(2^{\circ}\right)$ and these were attributed to amorphous silica, suggesting that Mag particles were successfully coated with silica using the simple co-precipitation method while the crystalline phase of $\mathrm{Fe}_{3} \mathrm{O}_{4}$ remained unchanged. The crystalline size (estimated from the Scherrer equation) of the $\mathrm{Fe}_{3} \mathrm{O}_{4}$ nanoparticles was also determined from the $\mathrm{X}$-ray line broadening using the (311) reflection (Table 1 ). The particle size was very small, around $8 \mathrm{~nm}$. Lemine et al. (2012) reported the synthesis of magnetite nanoparticles by sol-gel under ethanol supercritical conditions and obtained solids with an average size of $8 \mathrm{~nm}$ as well. This fact suggests that small $\mathrm{Fe}_{3} \mathrm{O}_{4}$ nanoparticles can be synthesized by a simple co-precipitation method and such small particles sizes are known to provide stronger superparamagnetic properties (Cornell et al., 2003).

Table 1.

Structural parameters of Mag and Mag/Si using powder X-ray diffraction data.

\begin{tabular}{llll}
\hline Solid & $\mathbf{d}_{001}(\mathbf{A})$ & $\mathbf{a}_{0}(\mathbf{A})$ & $\mathbf{D m}(\mathbf{n m})$ \\
\hline Mag & 2.51 & 8.32 & 8.14 \\
$\mathbf{M a g} / \mathbf{S i}$ & 2.52 & 8.36 & 7.76 \\
\hline
\end{tabular}

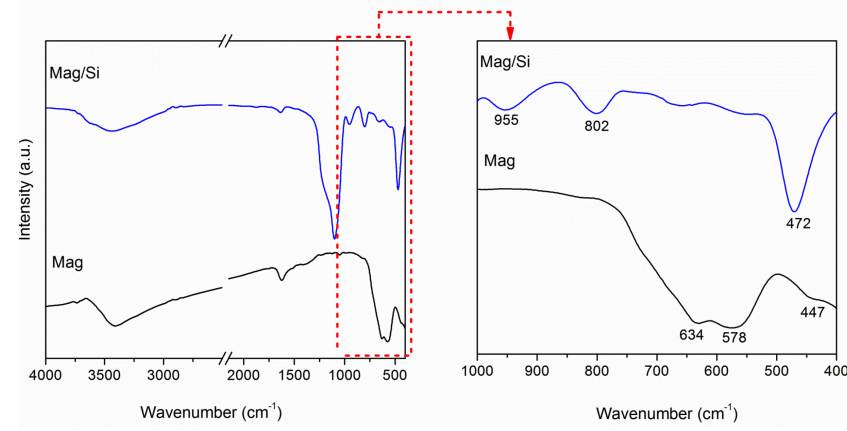

Fig.3. FTIR spectra of Mag before and after coating with $\mathrm{SiO}_{2}$ to produce the Mag/Si.

The solids were investigated by the FTIR spectroscopy as shown in Figure 3. The bands at $3500 \mathrm{~cm}^{-1}$ and $1600 \mathrm{~cm}^{-1}$ can be attributed to O-H stretching modes from adsorbed water molecules. Pure $\mathrm{Fe}_{3} \mathrm{O}_{4}$ (Mag) exhibited bands at $634 \mathrm{~cm}^{-1}, 578 \mathrm{~cm}^{-1}$, and $447 \mathrm{~cm}^{-1}$ that are attributable to Fe-O stretching vibration (Zhang et al., 2013). The silica coating was confirmed by the typical bands observed at $1100 \mathrm{~cm}^{-1}$ for $v_{\text {as }}(\mathrm{Si}-\mathrm{O}-\mathrm{Si}), 955$ $\mathrm{cm}^{-1}$ for $v(\mathrm{Si}-\mathrm{OH}), 802 \mathrm{~cm}^{-1}$ for $v_{\mathrm{s}}(\mathrm{Si}-\mathrm{O}-\mathrm{Si})$, and $472 \mathrm{~cm}^{-1}$ for $\delta(\mathrm{Si}-\mathrm{O}-\mathrm{Si})$ (Lopez et al., 2014; Ucoski et al., 2017).
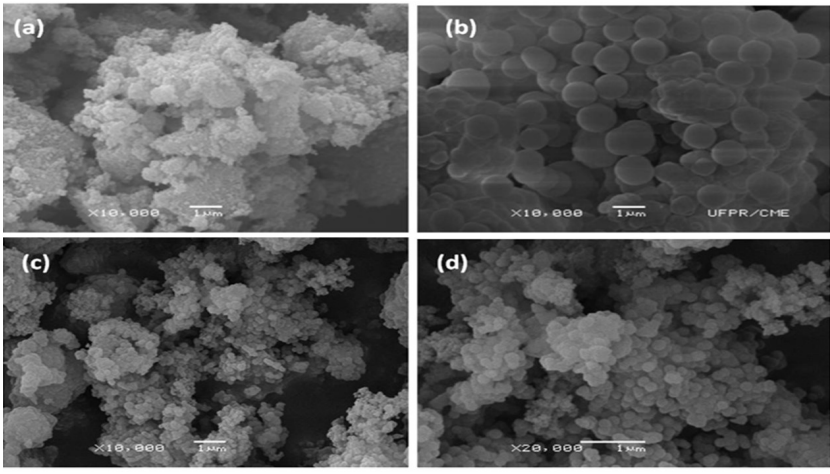

Fig.4. SEM images of (a) Mag and (b), (c), and (d) Mag/Si particles with different magnification values. 
SEM images are presented in Figure 4. In case of the Mag, the particles did not show a definite shape (Fig. 4a). However, after coating with silica, the resulting $\mathrm{Mag} / \mathrm{Si}\left(\mathrm{Fe}_{3} \mathrm{O}_{4} / \mathrm{SiO}_{2}\right)$ solids were spherical (Figs. 4b, 4c, 4d ), as expected for silica-coated magnetic particles prepared by the sol-gel hydrolytic process in alkaline medium (Stöber et al., 1968).

According to the TEM images (Fig. 5), both Mag (Fig. 5a) and Mag/Si particles (Fig. 5b, c, d) had a spherical morphology. As already mentioned above, this was expected in the latter case as a result of Mag coating with amorphous silica using the hydrolytic sol-gel process in basic media (Stöber et al., 1968). Figures 5c-d also demonstrate that Mag particles (darkest points of the images) were completely covered by amorphous silica (Silica - clearer image region) (Jacinto et al., 2008; Lopez et al., 2014; Ucoski et al., 2017).
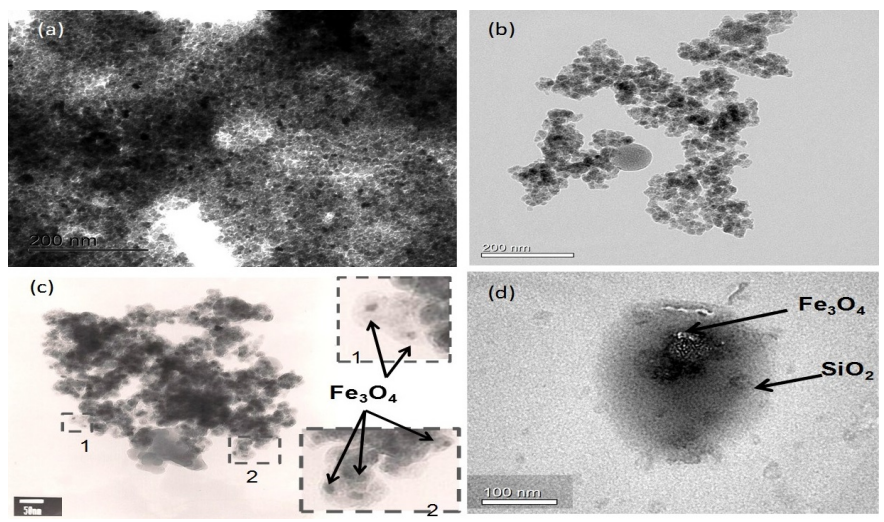

Fig.5. TEM images of (a) Mag and (b), (c), and (d) Mag/Si particles with different magnification values.

The presence of Mag in the Mag/Si solids was best evidenced by the bright and dark field images obtained for the same region of the sample (Fig. 6). In the dark field image (Fig. 6b), where only crystalline species were expected to diffract, clear areas were observed due to the electron diffraction caused by the presence of Mag particles, the only crystalline species in the Mag/Si solids. These particles appeared to be homogeneously dispersed in the sample when compared with the bright field image (Fig. 6a) (Ucoski et al., 2017).
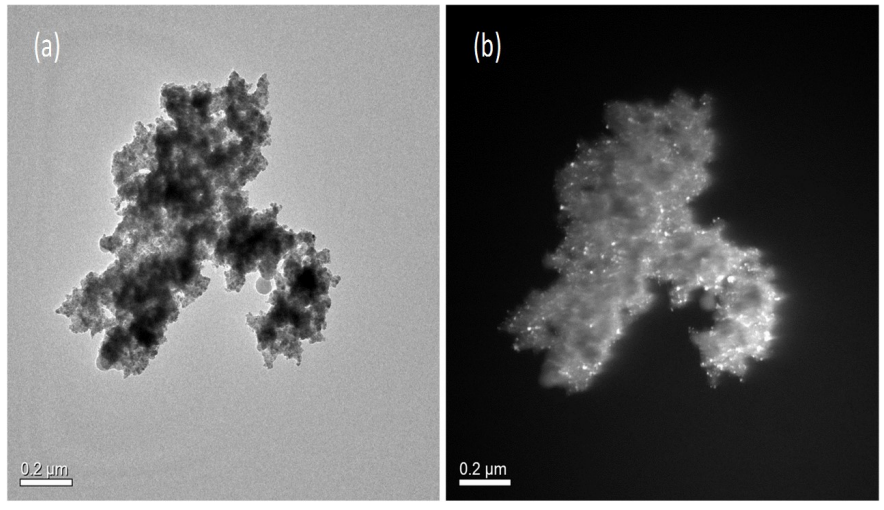

Fig.6. TEM images of Mag/Si particles in (a) bright and (b) dark field.

\subsection{Catalytic esterification reaction}

The catalytic performance of Mag and $\mathrm{Mag} / \mathrm{Si}$ was evaluated in the palmitic acid esterification with methanol under solvothermal conditions (Fig. 7). It has been observed that palmitic acid esterification under solvothermal reaction conditions $\left(120^{\circ} \mathrm{C}\right)$ led to a dramatic increase in conversion rate compared with the conventional conditions (Santos et al., 2015). Both solid catalysts showed

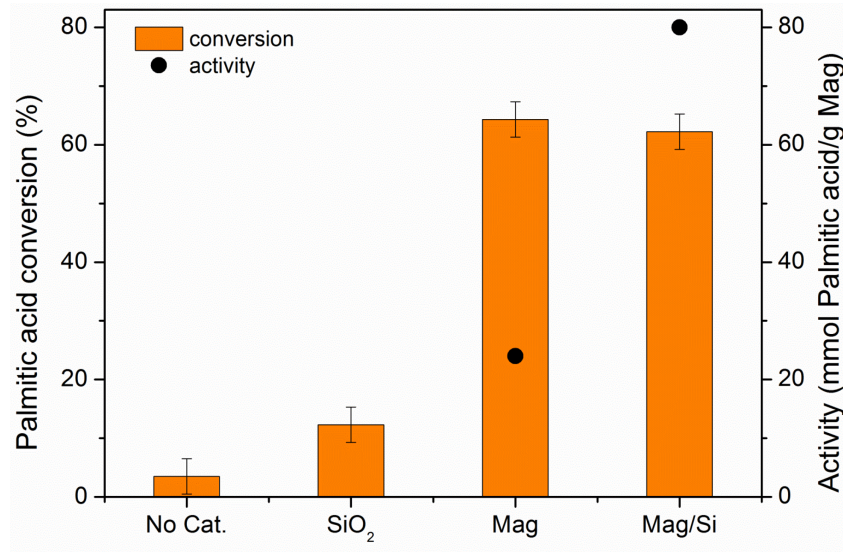

Fig.7. Catalytic activity of the magnetic nanoparticles in the esterification of palmitic acid with methanol. Conditions: $120^{\circ} \mathrm{C}, 12: 1$ (MeOH: palmitic acid), $10 \mathrm{wt} \%$ catalyst, $6 \mathrm{~h}$. The No Cat. bar refers to the control reaction without catalyst (Mag or Mag/Si), using only acid and alcohol under the same reaction conditions (Jing et al., 2015).

similar conversions, i.e., higher than $60 \%$ after $6 \mathrm{~h}$ of reaction. However, the catalytic activity in terms of mmol of palmitic acid converted normalized per $\mathrm{g}$ of Mag was more than 3 times higher for Mag/Si because it contained only 31 wt. $\%$ of $\mathrm{Fe}_{3} \mathrm{O}_{4}$ coated by silica. This result indicated the advantage of coating the nanoparticles with silica. The control reaction without any catalyst showed insignificant conversion (less than 5\%), suggesting that the catalytic activity was due to the presence of $\mathrm{Fe}_{3} \mathrm{O}_{4}$. Silica solid prepared herein presented low or moderate Brønsted acidity, not enough to promote more than $10 \%$ conversion after $6 \mathrm{~h}$, indicating the superior catalytic activity of pure or silica-coated $\mathrm{Fe}_{3} \mathrm{O}_{4}$ nano species.

An important feature of the catalytic solids investigated in this work was their easy removal from the reaction medium for reuse by using an external magnetic field (a simple magnet), without mass loss, eliminating the need for separation steps such as filtering or centrifuging. In terms of processing, this means large cost savings, both for equipment and energy consumption (Fig. 8). The stability and reusability of Mag and Mag/Si solid catalysts were also examined (Fig. 9 and Table 2).

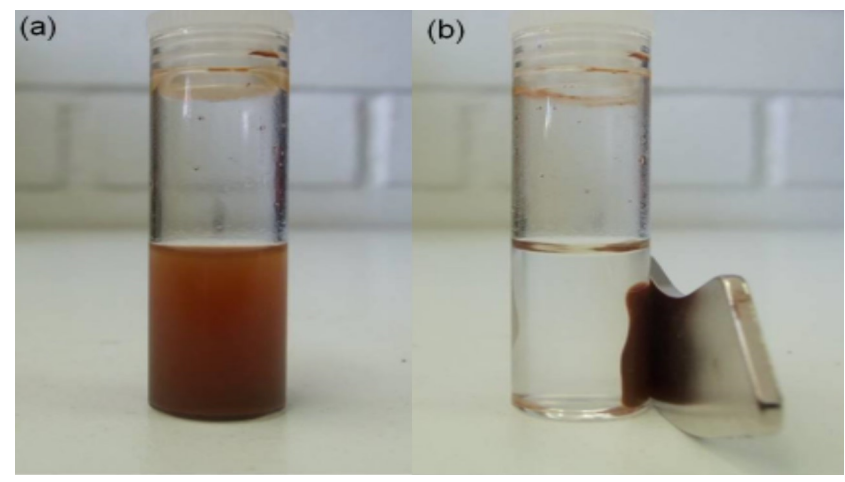

Fig.8. Images of the magnetic particles of the core-shell type (Mag/Si): (a) particles dispersed in alcohol, and (b) particles dispersed in alcohol after being attracted by an external magnetic field.

The solid catalysts were recovered after each reaction, exhaustively washed with methanol and subsequently reused in further esterification runs, which presented similar catalytic performance (Fig. 9). The solids were characterized after each reaction cycle by XRD and TEM (Figs. 10 and 11). The results presented in Figure 9 highlighted the stability of both Mag and Mag/Si solids. The catalytic activity in terms of conversion was maintained for up to four cycles. According to the XRD patterns for both 

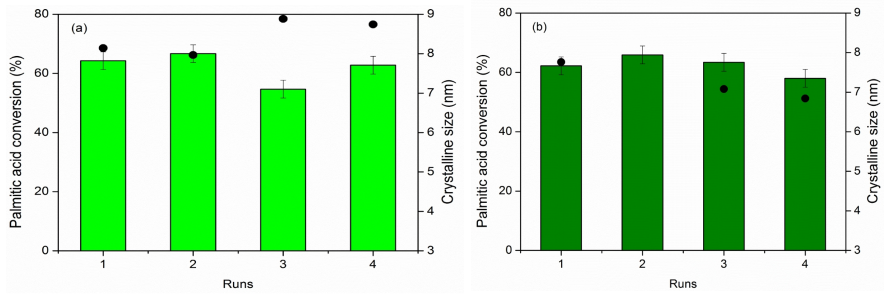

Fig.9. Catalytic recycling of (a) Mag and (b) Mag/Si (left axis) and their corresponding crystalline size estimated by Sherrer equation values (right axis).
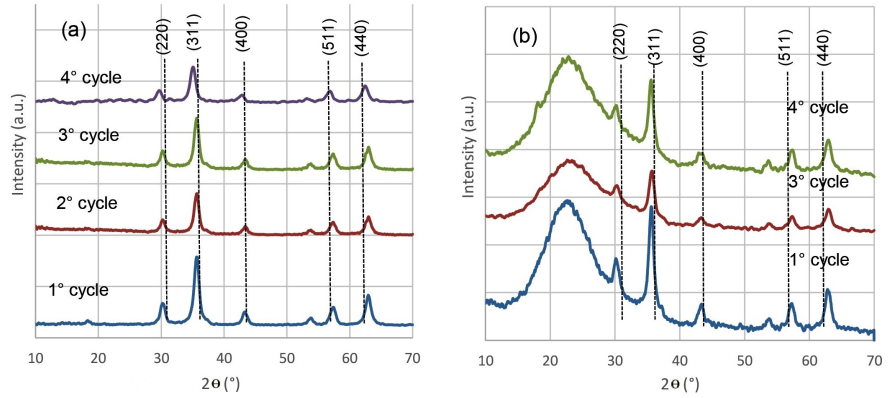

Fig.10. Powder X-ray diffraction patterns for (a) Mag and (b) Mag/Si following the recycling tests.

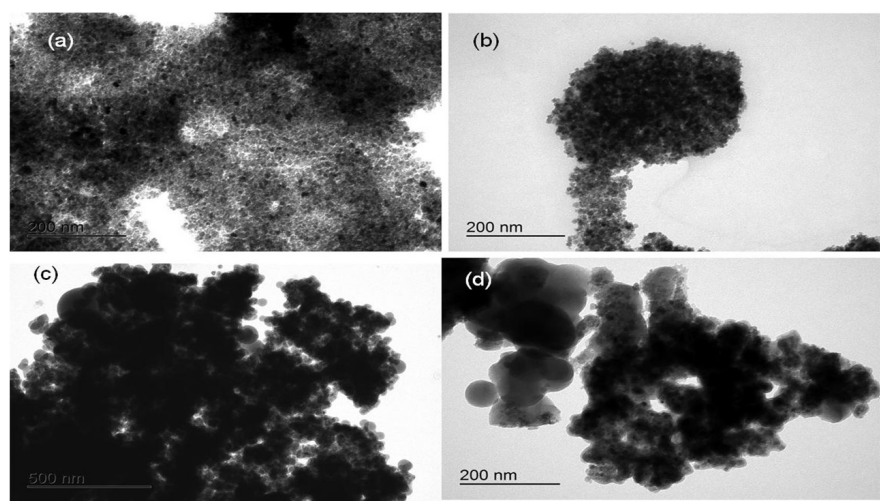

Fig.11. TEM images of Mag; (a) freshly synthesized and (b) after the $4^{\text {th }}$ reaction cycle, as well as, (c) fresh Mag/Si and (d) Mag/Si after the $4^{\text {th }}$ reaction cycles.

Mag and Mag/Si, the crystalline structure was almost the same, as also reported by Zhang et al. (2013). The crystalline size estimated using the Sherrer equation (Table 2) showed a slight increase after the third cycle for pure Mag, which can be attributed to some aggregation of free particles. However, after coating with silica $(\mathrm{Mag} / \mathrm{Si})$, the size of the particles was stabilized as was their crystalline structure, since the Bragg's d-spacing of $2.52 \AA$ corresponds to the most intensive peak of (311) at $35.42^{\circ}$ and the lattice parameters of $8.36 \AA$ were basically constant. For the pure nanoparticles, the d-spacing and lattice
Table 2.

Structural parameters of $\mathrm{Fe}_{3} \mathrm{O}_{4}$ and $\mathrm{Fe}_{3} \mathrm{O}_{4} / \mathrm{SiO}_{2}$ using powder X-ray diffraction data.

\begin{tabular}{llllllll}
\hline Catalytic & \multicolumn{4}{c}{ Mag } & & \multicolumn{4}{c}{ Mag/Si } \\
\cline { 2 - 4 } \cline { 7 - 8 } \cline { 7 - 8 } & $\mathrm{d}_{001}(\mathrm{~A})$ & $\mathrm{a}_{0}(\mathrm{~A})$ & $\mathrm{Dm}(\mathrm{nm})$ & & $\mathrm{d}_{001}(\mathrm{~A})$ & $\mathrm{a}_{0}(\mathrm{~A})$ & $\mathrm{Dm}(\mathrm{nm})$ \\
\hline $\mathbf{1}$ & 2.51 & 8.32 & 8.14 & & 2.52 & 8.36 & 7.76 \\
$\mathbf{2}$ & 2.52 & 8.34 & 7.97 & & - & - & - \\
$\mathbf{3}$ & 2.52 & 8.34 & 8.88 & & 2.51 & 8.35 & 7.10 \\
$\mathbf{4}$ & 2.56 & 8.49 & 8.74 & & 2.52 & 8.37 & 6.84 \\
\hline
\end{tabular}

parameters increased after the third cycle, suggesting particle agglomeration or changes in the structure of the crystalline phase (magnetite $\mathrm{Fe}_{3} \mathrm{O}_{4}$ and maghemite $\gamma-\mathrm{Fe}_{2} \mathrm{O}_{3}$ ) (Zhang et al., 2013).

The palmitic acid esterification reaction catalyzed by para-toluene sulfonic acid (PTSA) was also investigated under the same experimental conditions used for the catalysts Mag and Mag/Si (thermal conditions, 120 ${ }^{\circ} \mathrm{C}, 6 \mathrm{~h}$, acid/methanol molar ratio of $12: 1$, and $10 \%$ of catalyst in relation to the quantity of acid). PTSA is an acid catalyst that present good conversion values for esterification reaction (Ma et al., 1999; Hayyan et al. 2010; Tabatabaei et al., 2015) and has been shown to offer higher catalytic activity compared with benzenesulfonic acid and sulfuric acid (Guan et al. 2009). Under the above-mentioned conditions, the conversion observed was $97 \%$, similar to the results reported elsewhere for this reaction under different experimental conditions (Aafaqi et al., 2004; Hayyan et al., 2010 Barros et al., 2013; Tabatabaei et al., 2015). In spite of such a high value of conversion under acidic homogeneous conditions (homogeneous catalysis), acid catalysts generally present some inherent problems, e.g., higher cost (Hayyan et al., 2010) and being slower vs. basic catalyst in solution (Ma e al., 1999), corrosion, infeasible recovery/reuse, and the need for catalyst neutralization steps contributing to increased production of waste streams and consequent deterioration of the environmental aspects of the process (Paiva et al., 2015).

Moreover, Amberlyst 15 resin was also used as solid heterogeneous catalyst under similar reaction conditions used for PTSA. It is well documented that this ion-exchange resin presents high concentrations of acid sites (Hykkerud et al., 2016) and offers a catalytic activity comparable to other catalysts used in homogeneous and heterogeneous catalysis. In fact, under the experimental conditions applied herein (i.e., solvothermal), the conversion obtained using this solid stood at $97.5 \%$. Other studies have also reported on the application of this resin as catalyst for heterogeneous processes (Barros et al., 2013; Hykkerud et al., 2016). However, it should be noted that this resin presents poor thermal stability which could result in catalyst degradation and reduced activity after a single use depending on the experimental condition (Aafaqi et al., 2004; Hykkerud et al., 2016). This would in turn adversely affect the effective reuse of the catalyst.

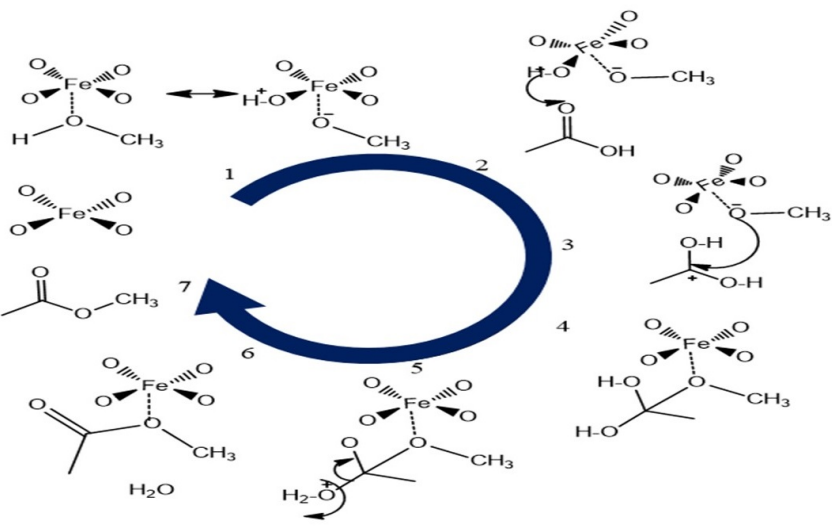

Fig.12. Proposed cooperative mechanism pathway involving Lewis and Brönsted acid sites for palmitic acid esterification with methanol (Choudary et al., 2000; Nakagaki et al., 2008; Karami et al., 2012) 
Magnetite nanoparticles have been employed as catalyst in many organic reactions and this has been attributed to the Lewis acid character of Fe $3 \mathrm{~d}$ orbitals (Koukabi et al., 2011; Karami et al., 2012; Mojtahedi et al., 2012: Parella et al., 2012). The esterification reaction follows a Brönsted acid catalyzed pathway. However, the presence of Lewis acid sites can promote the catalytic strength of Brönsted acids in a cooperative mechanism as illustrated in Figure 12. Initially, the Lewis acid sites polarize the alcohol $\mathrm{O}-\mathrm{H}$ bond followed by the abstraction of protons from methanol (1) and, in the next step, the Brönsted acid sites combine with the carbonyl oxygen from palmitic acid (2), making the carbonyl carbon susceptible to the attack of the electron pairs of the intermediate (1) in a nucleophilic reaction (3). The intermediates (4 and 5 ) lead to the formation of water, and after the desorption of methyl palmitate (6 and 7), the Brönsted and Lewis acid sites are regenerated, therefore completing the catalytic cycle (Choudary et al., 2000; Nakagaki et al., 2008; Karami et al., 2012).

\section{Conclusions}

Magnetic $\mathrm{Fe}_{3} \mathrm{O}_{4}$ or $\mathrm{Fe}_{3} \mathrm{O}_{4} / \mathrm{SiO}_{2}$ nanoparticles (solids $\mathrm{Mag}$ and $\mathrm{Mag} / \mathrm{Si}$ ) produced by a simple and inexpensive method exhibited a high catalytic activity for the esterification of palmitic acid with methanol under solvothermal conditions without the need for the presence of catalytic species traditionally used to catalyze this reaction. The developed catalysts were easily recovered from the reaction mixture for reuse in new catalytic cycles. The structure of the Mag catalytic species was maintained for at least four reaction cycles, and coating (Mag/Si) prevented crystal aggregation. Furthermore, the catalytic activity in terms of normalized mmol of palmitic acid conversion per $\mathrm{g}$ of Mag in the Mag/Si catalyst was more than three times higher than that of Mag nanoparticles. This finding revealed the advantage of coating the nanoparticules with silica. The obtained catalytic properties and stability suggested that the developed solids could be effectively used to replace mineral acids in some acid-catalyzed reactions such as fatty acid esterification, improving process sustainability by reducing costs and minimizing the environmental impact of downstream processing.

\section{Acknowledgments}

The authors are grateful to UFPR (Universidade Federal do Paraná) and to Conselho Nacional de Desenvolvimento Científico e Tecnológico - CNPq (grant 406737/2013-4 and post-doctoral fellowship of Geani M. Ucoski - CNPq grant 505110/2013-0 and 407152/2015-6) for providing financial support to carry out this study. Coordenação de Aperfeiçoamento de Pessoal de Nível Superior - CAPES is also acknowledged for providing graduate scholarships to Vannia Cristina dos Santos and Tailor Machado Peruzzolo. The authors are also grateful to Centro de Microscopia Eletrônica da UFPR for the SEM and TEM analyses and to Departamento de Física of UFPR for XRD analyses.

\section{References}

[1] Aafaqi, R., Mohamed, A.R., Bhatia, S., 2004. Kinetics of esterification of palmitic acid with isopropanol using p-toluene sulfonic acid and zinc ethanoate supported over silica gel as catalysts. J. Chem. Technol. Biotechnol. 79(10), 1127-1134.

[2] Andrade, M.F., Parussulo, A.L., Netto, C.G., Andrade, L.H., Toma, H.E., 2016. Lipase immobilized on polydopamine-coated magnetite nanoparticles for biodiesel production from soybean oil. Biofuel Res. J. 3(2), 403-409.

[3] Ansari, H.R., Curtis, A.J., 1974. Sesquiterpenes in the perfumery industry. J. Soc. Cosmet. Chem. 25(4), 203-231

[4] Avhad, M.R., Marchetti, J.M., 2016. Innovation in solid heterogeneous catalysis for the generation of economically viable and ecofriendly biodiesel: a review. Catal. Rev. Sci. Eng. 58(2), 157-208.

[5] Black, K.C., Yi, J., Rivera, J.G., Zelasko-Leon, D.C., Messersmith, P.B., 2013. Polydopamine-enabled surface functionalization of gold nanorods for cancer cell-targeted imaging and photothermal therapy. Nanomedicine. 8(1), 17-28.

[6] Barros, S.D., Coelho, A.V., Lachter, E.R., San Gil, R.A., Dahmouche, K., Silva, M.I.P., Souza, A.L., 2013. Esterification of lauric acid with butanol over mesoporous materials. Renew. Energ. 50, 585-589.
[7] Cano, M., Sbargoud, K., Allard, E., Larpent, C., 2012. Magnetic separation of fatty acids with iron oxide nanoparticles and application to extractive deacidification of vegetable oils. Green Chem. 14(6), 1786-1795.

[8] Cantrell, D.G., Gillie, L.J., Lee, A.F., Wilson, K., 2005. Structurereactivity correlations in $\mathrm{MgAl}$ hydrotalcite catalysts for biodiese synthesis. Appl. Catal., A. 287(2), 183-190.

[9] Carmo Jr, A.C., de Souza, L.K., da Costa, C.E., Longo, E., Zamian, J.R., da Rocha Filho, G.N., 2009. Production of biodiesel by esterification of palmitic acid over mesoporous aluminosilicate AlMCM-41. Fuel. 88(3), 461-468

[10] Chapuis, C., Jacoby, D., 2001. Catalysis in the preparation of fragrances and flavours. Appl. Catal., A. 221(1-2), 93-117.

[11] Chuah, L.F., Klemeš, J.J., Yusup, S., Bokhari, A., Akbar, M.M. 2017. A review of cleaner intensification technologies in biodiesel production. J. Cleaner Prod. 146, 181-193.

[12] Choudary, B.M., Kantam, M.L., Reddy, C.V., Aranganathan, S., Santhi, P.L., Figueras, F., 2000. Mg-Al-O-t-Bu hydrotalcite: a new and efficient heterogeneous catalyst for transesterification. J. Mol. Catal. A: Chem. 159(2), 411-416.

[13] Cornell, R.M., Schwertmann, U., 2003. The Iron Oxides: Structure Properties, Reactions, Occurences and Uses, 2nd ed. Wiley-VCH $\mathrm{GmbH} \& \mathrm{Co} . \mathrm{KgaA}$

[14] Demirbas, A., 2009. Progress and recent trends in biodiesel fuels. Energy Convers. Manage. 50(1), 14-34.

[15] dos Santos, V.C., Bail, A., Okada, H.D., Ramos, L.P., Ciuffi, K.J., Lima, O.J., Nakagaki, S., 2011. Methanolysis of soybean oil using tungsten-containing heterogeneous catalysts. Energy Fuels. 25(7), 2794-2802.

[16] Friák, M., Schindlmayr, A., Scheffler, M., 2007. Ab initio study of the half-metal to metal transition in strained magnetite. New J. Phys. 9(1), 5 .

[17] Frondel, M., Peters, J., 2007. Biodiesel: a new oildorado?. Energy Policy. 35(3), 1675-1684

[18] Gallezot, P., 2007. Catalytic routes from renewables to fine chemicals. Catal. Today. 121(1-2), 76-91.

[19] Guan, G., Kusakabe, K., Sakurai, N., Moriyama, K., 2009 Transesterification of vegetable oil to biodiesel fuel using acid catalysts in presence of dimethyl ether. Fuel. 88(1), 81-86.

[20] Gumba, R.E., Saallah, S., Misson, M., Ongkudon, C.M., Anton, A. 2016. Green biodiesel production: a review on feedstock, catalyst, monolithic reactor, and supercritical fluid technology. Biofuel Res. J. 3(3), 431-447

[21] Guo, P., Huang, F., Zheng, M., Li, W., Huang, Q., 2012. Magnetic solid base catalysts for the production of biodiesel. J. Am. Oil Chem. Soc. 89(5), 925-933

[22] Hayyan, A., Alam, M.Z., Mirghani, M.E., Kabbashi, N.A., Hakimi, N.I.N.M., Siran, Y.M., Tahiruddin, S., 2010. Sludge palm oil as a renewable raw material for biodiesel production by two-step processes. Bioresour. Technol. 101(20), 7804-7811.

[23] Hykkerud, A., Marchetti, J.M., 2016. Esterification of oleic acid with ethanol in the presence of Amberlyst 15. Biomass Bioenergy. 95 340-343.

[24] Jacinto, M.J., Kiyohara, P.K., Masunaga, S.H., Jardim, R.F., Rossi, L.M., 2008. Recoverable rhodium nanoparticles: synthesis, characterization and catalytic performance in hydrogenation reactions. Appl. Catal., A. 338(1-2), 52-57.

[25] Jing, H., Wang, X., Liu, Y., Wang, A., 2015. Preparation of magnetic nanocomposites of solid acid catalysts and their applicability in esterification. Chin. J. Catal. 36(2), 244-251.

[26] Karami, B., Hoseini, S.J., Eskandari, K., Ghasemi, A., Nasrabadi, H., 2012. Synthesis of xanthene derivatives by employing $\mathrm{Fe}_{3} \mathrm{O}_{4}$ nanoparticles as an effective and magnetically recoverable catalyst in water. Catal. Sci. Technol. 2(2), 331-338

[27] Knothe, G., Razon, L.S., 2017. Biodiesel fuels. Prog. Energy Combust. Sci. 58, 36-59

[28] Koukabi, N., Kolvari, E., Khazaei, A., Zolfigol, M.A., ShirmardiShaghasemi, B., Khavasi, H.R., 2011. Hantzsch reaction on free nano- $\mathrm{Fe}_{2} \mathrm{O}_{3}$ catalyst: excellent reactivity combined with facile 
catalyst recovery and recyclability. Chem. Commun. 47(32), 9230-9232.

[29] Lee, A.F., Bennett, J.A., Manayil, J.C, Wilson, K., 2014. Heterogeneous catalysis for sustainable biodiesel production via esterification and transesterification. Chem. Soc. Rev. 43(22), 7887-7916.

[30] Lee, H., Dellatore, S.M., Miller, W.M., Messersmith, P.B., 2007. Musselinspired surface chemistry for multifunctional coatings. Science. 318(5849), 426-430.

[31] Lemine, O.M., Omri, K., Zhang, B., El Mira, L., Sajieddine, M., Alyamani, A., Bououdina, M., 2012. Sol-gel synthesis of $8 \mathrm{~nm}$ magnetite $\left(\mathrm{Fe}_{3} \mathrm{O}_{4}\right)$ nanoparticles and their magnetic properties. Superlattices Microstruct. 52(4), 793-799

[32] Lenardão, E.J., Botteselle, G.V., Azambuja, F., Perin, G., Jacob, R.G., 2007. Citronellal as key compound in organic synthesis. Tetrahedron. 63(29), 6671-6712.

[33] Lois, E., 2007. Definition of biodiesel. Fuel. 86(7-8), 1212-1213.

[34] Lopez, C., Cruz-izquierdo, A., Picó, E.A., García-bárcena, T., Villarroel, N., Llama, M.J., Serra, J.L., 2014. Magnetic biocatalysts and their uses to obtain biodiesel and biosurfactants. Front. Chem. 2, 72

[35] Ma, F., Hanna, M.A., 1999. Biodiesel production: a review. Bioresour. Technol. 70(1), 1-15

[36] Mansoori, Y., Tataroglu, F.S., Sadaghian, M., 2005. Esterification of carboxylic acids by tributyl borate under solvent- and catalyst-free conditions. Green Chem. 7(12), 870-873.

[37] Mojtahedi, M.M., Abaee, M.S., Rajabi, A., Mahmoodi, P., Bagherpoor, S., 2012. Recyclable superparamagnetic $\mathrm{Fe}_{3} \mathrm{O}_{4}$ nanoparticles for efficient catalysis of thiolysis of epoxides. J. Mol. Catal. A: Chem. 361-362, 6871.

[38] Monteiro, J.L.F., Veloso, C.O., 2004. Catalytic conversion of terpenes into fine chemicals. Top. Catal. 27(1-4), 169-180.

[39] Nakagaki, S., Bail, A., Santos, V.C., Souza, V.H.R., Vrubel, H., Nunes, F.S., Ramos, L.P., 2008. Use of anhydrous sodium molybdate as an efficient heterogeneous catalyst for soybean oil methanolysis. Appl. Catal., A. 351(2), 267-274.

[40] Nishikubo, T., Kameyama, A., Yamada, Y., Yoshida, Y., 1996. Synthesis of polymers in aqueous solutions: esterification reaction of poly (methacrylic acid) with alkyl halides using DBU in aqueous solutions. J. Polym. Sci. Part A Polym. Chem. 34(17), 3531-3537.

[41] Paiva, E.J.M., Sterchele, S., Corazza, M.L., Murzin, D.Y., Wypych, F., Salmi, T., 2015. Esterification of fatty acids with ethanol over layered zinc laurate and zinc stearate - Kinetic modeling. Fuel. 153, 445-454.

[42] Parella, R., Babu, S.A., 2012. Magnetic nano $\mathrm{Fe}_{3} \mathrm{O}_{4}$ and $\mathrm{CuFe}_{2} \mathrm{O}_{4}$ as heterogeneous catalysts: a green method for the stereo-and regioselective reactions of epoxides with indoles/pyrroles. Catal. Commun. 29, 118121.

[43] Philipse, A.P., Van bruggen, M.P., Pathmamanoharan, C., 1994. Magnetic silica dispersions: preparation and stability of surface-modified silica particles with a magnetic core. Langmuir. 10(1), 92-99.

[44] Polshettiwar, V., Luque, R., Fihri, A., Zhu, H., Bouhrara, M., Basset, J.M., 2011 Magnetically Recoverable Nanocatalysts. Chem. Rev. 111(5), 3036-3075

[45] Ren, Y., Rivera, J.G., He, L., Kulkarni, H., Lee, D.K., Messersmith, B.P., 2011. Facile, high efficiency immobilization of lipase enzyme on magnetic iron oxide nanoparticles via a biomimetic coating. BMC Biotechnol. 11(1), 63-70

[46] Rossi, L.M., Garcia, M.A., Vono, L.L., 2012. Recent advances in the development of magnetically recoverable metal nanoparticle catalysts. J. Braz. Chem. Soc. 23(11), 1959-1971.

[47] Santos, V.C., Wilson, K., Lee, A.F., Nakagaki, S., 2015. Physicochemical properties of $\mathrm{WO}_{\mathrm{x}} / \mathrm{ZrO}_{2}$ catalysts for palmitic acid esterification. Appl. Catal., B. 162, 75-84.

[48] Santos, L.K., Cestari, A., 2014. Synthetic and reusable potassium aluminate heterogeneous catalyst for biodiesel production. Rev. Virtual Química. 6(4), 1021-1032.
[49] Schwab, W., Fuchs, C., Huang, F.C., 2013. Transformation of terpenes into fine chemicals. Eur. J. Lipid Sci. Technol. 115(1), 3-8.

[50] Semwal, S., Arora, A.K., Badoni, R.P., Tuli, D.K., 2011. Biodiesel production using heterogeneous catalysts. Bioresour. Technol, 102(3), 2151-2161.

[51] Serri, N.A., Kamaruddin, A.H., Len, K.Y.T., 2010. A continuou esterification of malonic acid with citronellol using packed bed reactor: investigation of parameter and kinetics study. Food Bioprod. Process. 88(2-3), 327-332

[52] Silva, A., Wilson, K., Lee, A.F., Santos, V.C., Bacilla, A.C.C., Mantovani, K.M., Nakagaki, S., 2017. $\mathrm{Nb}_{2} \mathrm{O}_{5} / \mathrm{SBA}-15$ catalyzed propanoic acid esterification. Appl. Catal., B. 205, 498-504.

[53] Stöber, W., Fink, A., Bohn, E., 1968. Controlled growth of monodisperse silica spheres in the micron size range. J. Colloid Interface Sci. 26(1), 62-69.

[54] Tabatabaei, M., Karimi, K., Horváth, I., Kumar, R., 2015. Recent trends in biodiesel production. Biofuel Res. J. 2(3), 258-267.

[55] Tang, S., Wang, L., Zhang, Y., Li, S., Tian, S., Wang, B., 2012. Study on preparation of $\mathrm{Ca} / \mathrm{Al} / \mathrm{Fe}_{3} \mathrm{O}_{4}$ magnetic composite solid catalyst and its application in biodiesel transesterification. Fuel Process. Technol. 95, 84-89

[56] Ucoski, G.M., Pinto, V.H.A., DeFreitas-Silva, G., Rebouças, J.S. Mazzaro, I., Nunes, F.S., Nakagaki, S., 2017. Magnetic HMS silica as a support to immobilization of catalysts based on cationic manganese porphyrins. ChemistrySelect. 2(13), 3703-3715.

[57] Ucoski, G.M., Nunes, F.S., Defreitas-silva, G., Idemori, Y.M Nakagaki, S. 2013 Metalloporphyrins immobilized on silica-coated $\mathrm{Fe}_{3} \mathrm{O}_{4}$ nanoparticles: magnetically recoverable catalysts for the oxidation of organic substrates. Appl. Catal., A. 459, 121-130.

[58] Wang, H., Song, Y., Wang, Z., Medforth, C.J., Miller, J.E., Evans, L., Li, P., Shelnuttt, J.A., 2008. Silica-Metal Core-Shells and Metal Shells Synthesized by Porphyrin-Assisted Photocatalysis. Chem. Mater. 20(24), 7434-7439

[59] Xu, C., Xu, K., Gu, H., Zheng, R., Liu, H., Zhang, X., Guo, Z., Xu, B., 2004. Dopamine as a robust anchor to immobilize functional molecules on the iron oxide shell of magnetic nanoparticles. J. Am. Chem. Soc. 126(32), 9938-9939.

[60] Yadav, G.D., Lathi, P.S., 2004. Synthesis of citronellol laurate in organic media catalyzed by immobilized lipases: kinetic studies. J. Mol. Catal. B: Enzym. 27(2-3), 113-119.

[61] Yan, S., Salley, S.O., Ng, K.Y.S., 2009. Simultaneous transesterification and esterification of unrefined or waste oils over ZnO- $\mathrm{La}_{2} \mathrm{O}_{3}$ catalysts. Appl. Catal., A. 353(2), 203-212.

[62] Yang, C., Wu, J., Hou, Y., 2011. $\mathrm{Fe}_{3} \mathrm{O}_{4}$ nanostructures: synthesis, growth mechanism, properties and applications. Chem. Commun. 47(18), 5130-5141.

[63] Yi, D.K., Lee, S.S., Papaefthymiou, G.C., Ying, J.Y., 2006 Nanoparticle architectures templated by $\mathrm{SiO}_{2} / \mathrm{Fe}_{2} \mathrm{O}_{3}$ nanocomposites. Chem. Mater. 18(3), 614-619

[64] Zhang, H., Ding, J., Qiu, Y., Zhao, Z., 2012. Kinetics of esterification of acidified oil with different alcohols by a cation ion-exchange resin/polyethersulfone hybrid catalytic membrane. Bioresour. Technol. 112, 28-33.

[65] Zhang, Y., Dubé, M.A., McLean, D.D., Kates, M., 2003. Biodiesel production from waste cooking oil: 1. Process design and technological assessment. Bioresour. Technol. 89(1), 1-16.

[66] Zhang, X., Niu, Y., Meng, X., Li, Y., Zhao, J., 2013. Structura evolution and characteristics of the phase transformations between $\alpha$ $\mathrm{Fe}_{2} \mathrm{O}_{3}, \mathrm{Fe}_{3} \mathrm{O}_{4}$ and $\gamma-\mathrm{Fe}_{2} \mathrm{O}_{3}$ nanoparticles under reducing and oxidizing atmospheres. CrystEngComm. 15(40), 8166-8172. 